\title{
HOMENS COM DIAGNÓSTICO DE CÂNCER DE PRÓSTATA: ENFRENTAMENTOS E ADAPTAÇÕES
}

\author{
MEN WITH PROSTATE CANCER DIAGNOSIS: CHALLENGES AND ADAPTATIONS
}

\section{Daiane Pereira Serafimª, Lacir Marli Wagner Cardozo ${ }^{\mathrm{b}}$, Beatriz Schumacher}

adaiane.p.ser@hotmail.com, blacir_marli@hotmail.com, cbeatriz.schumacher@ielusc.br Instituto Superior e Centro Educacional Luterano Bom Jesus - Joinville (SC), Brasil

Data de recebimento do artigo: 06/01/2017 Data de aceite do artigo: 29/06/2017

\section{RESUMO}

Introduçáo: $\mathrm{O}$ câncer de próstata é considerado uma neoplasia maligna, sendo o segundo tipo mais comum na população masculina. É uma doença carregada de preconceitos e estigmas, pois muitas vezes o homem sente-se isolado, afastando-se do convívio social. Objetivos: Conhecer as formas de enfrentamento e/ou adaptaçôes dos homens diagnosticados com câncer de próstata, atendidos no ambulatório de oncologia de um hospital público em Joinville (SC). Metodologia: Trata-se de um estudo do tipo exploratório, com abordagem qualitativa. Foram entrevistados dez homens, com idade entre 48 a 76 anos, diagnosticados com câncer de próstata, em tratamento. A coleta de dados foi realizada por meio de um questionário semiestruturado, com dados de identificação e perguntas relacionadas à temática do estudo, no período de maio e junho de 2016. Resultados: Identificamos que a idade da maioria dos homens diagnosticados com câncer de próstata está entre 60 e 65 anos; assim como alguns autores referem esse tipo de câncer como o da terceira idade. Foram também encontrados alguns fatores de risco predisponentes. A partir dos relatos dos participantes pôde-se compreender que, quando diagnosticados com câncer de próstata, os homens vivenciam momentos difíceis e dos quais emergem alguns sentimentos, como: negação, preconceito, tristeza e medo da morte, entre outros. Muitos apresentam impotência sexual. Conclusóes: Situaçóes de conflitos individuais e familiares exigem formas de enfrentamentos e adaptaçóes no convívio familiar. O maior impacto relatado está relacionado à sexualidade. No entanto, revelam a importância do apoio familiar e religioso na adesão ao tratamento.

Palavras-chave: Homem; enfermagem; câncer de próstata; tratamento.

\section{ABSTRACT}

Introduction: Prostate cancer is considered a malignant neoplasm, being the second most common type in the male population. It is a disease fraught with prejudices and stigmata, because the man often feels isolated, moving away from the social life. Objectives: To know the ways of coping with and/or the adaptations of men diagnosed with prostate cancer, attended at the oncology clinic of a public hospital in Joinville (SC), Brazil. Methodology: This is an exploratory study with a qualitative approach. Ten men, aged 48 to 76 years, diagnosed with prostate cancer, were interviewed. Data collection was performed through a semi-structured questionnaire, with identification data and questions related to the study theme, in the period of May and June of 2016. Results: We identified that most men were aged between 60 and 65 years, hence this type of cancer being of the third age, as some authors refer. Some predisposing risk factors were also found. When we consider the reports of the participants we can understand that when diagnosed with prostate cancer, men experience difficult moments from which some feelings emerge, such as denial, prejudice, sadness and fear of death, among others. Many have sexual impotence. Conclusions: Situations of individual and family conflicts require ways of coping with and adaptation in family life. The greatest reported impact is related to sexuality. However, they reveal the importance of family and religious support in adhering to treatment.

Keywords: Man; nursing; treatment of prostate cancer. 


\section{Introdução}

A palavra "câncer" (CA) é frequentemente utilizada para definir um conjunto de mais de 100 tumores que têm em comum o crescimento desordenado (maligno) e acelerado de células que podem invadir os tecidos e órgãos, espalhando-se (metástase) para outras áreas do organismo humano ${ }^{1}$. No Brasil e no mundo, a incidência de câncer vem aumentando rapidamente e está associada aos hábitos e à maior expectativa de vida da população.

O câncer de próstata é uma neoplasia maligna, classificado como o segundo tipo mais comum na população masculina, acometendo geralmente homens acima de 50 anos, principalmente os de 65 anos ou mais, com histórico familiar de CA de próstata, considerado por muitos especialistas o câncer da terceira idade ${ }^{2}$.

O Instituto Nacional do Câncer (Inca) refere que a fase primária ou desenvolvimento do câncer de próstata é silencioso ${ }^{3}$. Normalmente muitos homens não apresentam sintomas. No entanto, quando aparecem, são similares ao crescimento benigno da próstata, causando dificuldade para urinar ou necessidade de urinar várias vezes durante o dia ou principalmente à noite. O estágio avançado pode ser caracterizado por dor óssea, distúrbios urinários, infecção generalizada ou insuficiência renal.

Os tratamentos medicamentosos, como a hormonioterapia, causam alteraçóes no organismo, prejudicando a autoimagem do homem. Entre as mais frequentes estão a diminuição da libido e o aumento do volume das mamas ${ }^{2}$.

Vale destacar que a próstata é um órgão que representa, no imaginário sociocultural, a masculinidade do homem; portanto, o sentimento de depressão e a impotência sexual estão presentes na maioria dos casos da doença, mesmo quando essa impotência é por um curto prazo ${ }^{4}$.

Existem múltiplos fatores que indicam a alta incidência de câncer de próstata, desde a maior expectativa de vida até influências ambientais e alimentares, como a ingestão de carne vermelha, o alto consumo de gordura, o tabagismo, o consumo de álcool e o histórico familiar, entre outros ${ }^{3}$.

Acompanhar o processo de adoecimento não é uma tarefa fácil, em especial com os homens que, geralmente, não têm o hábito de cuidar da saúde. Considerando esse contexto, cabe aos profissionais o desenvolvimento de ações de promoção à saúde e prevenção de doenças, bem como conhecer o paciente, seus familiares, suas necessidades, sua cultura e apoiá-los no cuidado com a saúde.

Para Gianini ${ }^{5}$, os avanços na área da saúde permitem que a pessoa conviva com uma doença crônica sem perda da qualidade de vida, apesar da crise vital que o câncer pode provocar no indivíduo e na família. Entendemos que a doença exige enfrentamento e readaptaçóes. Assim, conhecer as percepçóes dos homens oferece subsídios aos profissionais de saúde para melhorar a assistência.

Muitas vezes, a doença é avassaladora e pode acarretar necessidades de adaptação, em função das alteraçóes físicas e psicológicas durante seu tratamento. Assim, entendemos a importância de um atendimento humanizado e individualizado com o homem, pois os sentimentos com o diagnóstico são diferentes para cada pessoa $^{2}$, uma vez que o sofrimento do homem com câncer de próstata pode afetar seu bem-estar físico e emocional.

Dessa forma, entendemos ser de grande relevância a proposta deste estudo, que possibilita a construção de espaços de reflexão sobre a promoção da saúde do homem, compreendendo que a prevenção e o diagnóstico precoce são considerados estratégias fundamentais para o controle do câncer de próstata.

\section{Metodologia}

Este é um estudo exploratório realizado em 2016, com abordagem qualitativa, para possibilitar uma melhor compreensão sobre as formas de enfrentamentos e/ ou adaptaçóes dos homens diagnosticados com câncer de próstata.

No intuito de alcançar os objetivos deste estudo, foram estabelecidos critérios de inclusão para a composição do grupo de pessoas participantes da pesquisa. Foram incluídos os homens que atenderam aos seguintes critérios: acima de 40 anos de idade, diagnosticados com câncer de próstata, aceitar participar da pesquisa e assinar o termo de consentimento livre e esclarecido.

A coleta de dados foi realizada durante os meses de junho e julho de 2016. Os dados que compóem o perfil social e demográfico dos participantes foram obtidos por meio das respostas às perguntas de um questionário utilizado nas entrevistas.

Esta pesquisa foi aprovada pela banca de professoras e pelo Comitê de Ética em Pesquisa do Instituto Superior e Centro Educacional Luterano Bom Jesus/ Ielusc, sob parecer favorável $\mathrm{n}^{\circ} 1.521 .594$, de 20 de abril de 2016.

Antes de iniciar a coleta de dados, realizamos um pré-teste inicial com três homens internados na ala de oncologia do hospital. Em seguida, foram realizadas algumas modificações no instrumento.

Participaram desta pesquisa dez homens, com idade entre 48 e 76 anos, diagnosticados com câncer 
de próstata, em tratamento no ambulatório de oncologia de um hospital público localizado na cidade de Joinville.

Para garantir seu anonimato, os participantes da pesquisa foram identificados pelas letras A, B, C, D, E, F, G, H, I e J, respeitando a Resolução no 466/2012.

As entrevistas foram agendadas de acordo com a disponibilidade dos participantes via contato telefônico e diretamente no ambulatório; dessa forma foram definidos data e horário dos encontros, que tiveram duração de aproximadamente 40 minutos e cujas as respostas foram transcritas.

Inicialmente, os participantes foram informados sobre os objetivos da pesquisa e da metodologia. A entrevista realizou-se por meio de um questionário semiestruturado, com 15 questóes abertas e fechadas.

Realizadas as entrevistas, alguns dados foram compilados em planilhas do programa Microsoft Excel, e as áreas temáticas foram estruturadas após a leitura das respostas das questóes abertas.

Os dados foram interpretados por meio da análise temática proposta por Minayo $^{6}$, que contempla três etapas: pré-análise, exploração do material e tratamento dos resultados obtidos e interpretação:

1. Pré-análise: consiste na escolha dos documentos para orientar a interpretação final.

2. Exploração do material: nesta etapa codificamos o material dos questionários agrupando-os por similaridade e dimensóes temáticas.

3. Tratamento dos resultados obtidos e interpretação: os resultados brutos foram submetidos a operaçóes estatísticas simples (porcentagem), e as dimensões temáticas, comparadas com a literatura.

\section{Resultados e discussão}

Este estudo foi realizado com a participação de dez homens, atendidos no ambulatório de oncologia de um hospital público de Joinville, entrevistados no decorrer dos meses de junho e julho de 2016. As áreas temáticas identificadas nesta pesquisa foram: 1) a descoberta da doença; 2) a agressividade do tratamento; 3) mudanças no estilo de vida: um longo caminho; 4) família: o câncer em nossas vidas; 5) o câncer de próstata e as redes de apoio; 6) percepçóes e sentimentos dos homens diagnosticados com câncer de próstata.

\section{Características dos participantes}

A seguir, serão apresentados os dados de identificação dos participantes da pesquisa.
Tabela 1: Distribuição da idade dos participantes diagnosticados com câncer de próstata.

\begin{tabular}{|ccc|}
\hline Idade & $\mathbf{N}$ & $\%$ \\
\hline $45-50$ & 1 & 10 \\
\hline $50-55$ & - & 0 \\
\hline $55-60$ & 2 & 20 \\
\hline $60-65$ & 3 & 30 \\
\hline $65-70$ & 2 & 20 \\
\hline $70-75$ & 1 & 10 \\
\hline $75-80$ & 1 & 10 \\
\hline TOTAL & 10 & 100 \\
\hline
\end{tabular}

Na Tabela 1 observamos que a média de idade dos participantes foi de 57 anos de idade, com a idade mínima de 48 anos e máxima de 76 anos, com maior incidência da doença em homens acima de 55 anos (3).

Quanto à escolaridade, o estudo demonstra que $40 \%$ dos participantes têm o ensino fundamental incompleto, 30\% têm ensino fundamental completo, e $30 \%$, o ensino médio completo. Esses dados são semelhantes aos encontrados na literatura por Gonçalves, Padovani e Popim 7 , que apontam a baixa escolaridade como característica em geral apresentada pelos homens com câncer; porém, em sua maioria, revelam algum grau de instruçãa.

Em relação ao estado civil, observamos que 80\% dos participantes são casados e que $20 \%$ são separados, achados também semelhantes aos encontrados na literatura. Estima-se que um em cada dez homens desenvolve carcinoma de próstata, clinicamente evidente, e que a incidência maior ocorre em pessoas com idades mais avançadas, predominantemente, entre homens casados ${ }^{7}$.

A renda familiar dos participantes variou entre $\mathrm{R} \$ 880,00$ e $\mathrm{R} \$ 2.200,00$, com média de 1,34 salário mínimo. Vale destacar que $60 \%$ dos participantes são arrimo familiar e $40 \%$ contam com a participação dos familiares na renda doméstica.

No que se refere à religiáo, $70 \%$ dos participantes são católicos e revelam ser espiritualizados e acreditar em Deus, ou seja, em um ser superior. Já $20 \%$ dos participantes mencionam não ter uma crença/religiáo específica e $10 \%$ são evangélicos. Para Fornazari e Ferreira $^{8}$, a influência religiosa ou espiritual pode auxiliar e intensificar a adesáo ao tratamento, contribuindo no enfrentamento da doença, reduzindo o estresse e a ansiedade.

\section{Área temática 1 - A descoberta da doença}

Neste estudo, no que diz respeito à descoberta da doença, três dos participantes referem que tiveram 
diagnóstico precoce $^{1}$, e os outros sete, diagnóstico $\operatorname{tardio}^{2}$

O diagnóstico precoce do câncer de próstata aumenta as chances de sucesso no tratamento da doença. Porém, segundo o A.C. Camargo Cancer Center', quase um terço dos pacientes acometidos por essa afecçáo já apresentavam tumor avançado ou metastático. Assim, os homens precisam receber um tratamento mais agressivo, pois o controle local da doença é inviável ${ }^{10}$.

Bastian Júnior ${ }^{11}$ menciona que as estatísticas brasileiras na área da saúde ainda são incompletas, logo, muitas vezes é necessário recorrer aos dados apresentados pelos países da América do Norte e da Europa, nos quais o registro nosológico é realizado de forma mais consistente. De acordo com os índices divulgados por esses países, estima-se que em 2025 haja o dobro de pacientes com doença metastática e um incremento de $13 \%$ a $20 \%$ no número de mortes evitáveis por câncer de próstata. Ou seja, mesmo nos países considerados desenvolvidos, ainda prevalece o diagnóstico tardio.

Nessa perspectiva, é importante incentivar campanhas educativas, promovendo açóes que favoreçam o diálogo sobre o câncer de próstata e medidas de prevenção, a fim de sensibilizar os usuários. Quanto mais precocemente o câncer de próstata é diagnosticado e quanto antes se inicia seu tratamento, maiores e melhores serão as possibilidades de cura, além do tratamento ser menos agressivo e de menor custo comparado aos em estágios mais avançados ou com metástase ${ }^{12}$.

O pouco conhecimento dos homens sobre a doença, o medo da constataçáo e as dificuldades de acesso ao sistema de saúde são fatores agravantes para o atraso no diagnóstico. Assim, as equipes de saúde são essenciais para o diagnóstico do câncer e precisam estar sensibilizadas quanto a essa responsabilidade.

As atividades de prevenção auxiliam no processo de identificação precoce da doença. Portanto, os profissionais precisam estar atentos e verificar os exames de detecção prévia de câncer e outras doenças associadas, e também incentivar e sensibilizar os pacientes sobre a importância do homem aprender a cuidar da saúde ${ }^{13}$.

\section{Área temática 2 - $A$ agressividade do tratamento}

Os tratamentos para o câncer de próstata podem causar efeitos colaterais desagradáveis e angustiantes, em curto ou em longo prazo. Em relação aos vários

\footnotetext{
${ }^{1}$ Neste estudo, consideramos câncer precoce aquele que acomete apenas um órgão do corpo.

${ }^{2}$ Neste estudo, consideramos diagnóstico tardio quando acontece o processo metastático do câncer (prolifera-se para outros órgãos)
}

tipos de tratamentos realizados pelos participantes, observamos que muitos citaram apenas datas aproximadas: 5 dos homens iniciaram o tratamento no período de 1 a 3 anos após o diagnóstico, 3 dos participantes após um ano, e 2 estavam iniciando no dia da entrevista.

A prostatectomia é um procedimento cirúrgico para tratamento do câncer de próstata e pode trazer complicaçóes como incontinência urinária e disfunção erétil, formação de coágulos que causam a obstrução do cateter e até distender a cápsula prostática e provocar hemorragia. Além disso, o paciente submetido à cirurgia muitas vezes vivencia conflitos emocionais como medo, desamparo, raiva e tristeza. Essas complicações podem ser agravadas pelas expectativas pós-operatórias e dúvidas sobre o tratamento ${ }^{14}$.

Esses efeitos colaterais são evidenciados pelas seguintes falas:

Novembro pra cá, tô tomando medicaçäo para urinar [...]. (Participante $\mathrm{H}$ )

Iniciei com a químio, depois com quatro injeçōes de três em três meses, e hoje tô iniciando a radioterapia [...]. (Participante D)

Fiquei uns três dias sem andar, travou as pernas, não saía a urina, dá vontade e não sai. Tive infecção urinária e ainda arde [...]. (Participante B)

Batista, Mattos e $\mathrm{Silva}^{15}$ ressaltam que pacientes submetidos ao tratamento de câncer podem sentir dor, náuseas e vômitos e apresentar queda de cabelo, alteraçôes de peso, fadiga e ansiedade. Essa constatação é evidenciada na seguinte fala:

Tive algumas reaçöes durante o tratamento, como tontura, pequena dor de cabeça e desânimo [...]. (Participante F)

Esses sintomas podem influenciar na qualidade de vida dos pacientes oncológicos, interferindo no humor, mobilidade, sono, alimentação e atividades diárias de forma geral. Além disso, outros efeitos colaterais do tratamento oncológico, como anorexia, depressão, ansiedade, constipação, disfagia, dispneia e astenia afetam as relaçóes sociais, familiares e profissionais desses indivíduos ${ }^{15}$.

Apesar da terapia de privação hormonal melhorar os resultados terapêuticos do câncer de próstata, ela aumenta efeitos colaterais como fadiga, perda da libido, diminuição da densidade óssea, alterações musculares, anemia, fogachos e, possivelmente, complicaçôes cardiovasculares ${ }^{16}$, que podemos observar nos seguintes relatos dos participantes: 
Estou fazendo hormonioterapia, já fiz três doses e tenho impotência sexual [...]. (Participante G)

Fiz cirurgia e, um ano depois, usei tadalafila, orientação do doutor. O que mudou, eu era uma pessoa muito ativa sexual, mas fazer o que, é outra coisa [...]. (Participante J)

Segundo Sanchez et al. ${ }^{17}$, mulheres relataram que seus maridos, com câncer de próstata, vivenciaram a impotência sexual ou incontinência urinária duradouras como resultado do tratamento realizado, e esses efeitos colaterais causaram transtornos na vida diária do casal. Em relação às mudanças mais relevantes, quatro homens relataram sobre as disfunções sexuais:

Na minha vida foi a parte do sexo [...]. (Participante A)

Na atividade sexual [...]. (Participante G)

Mudou bastante até na parte da cama, eu com a esposa [...]. (Participante $\mathrm{H}$ )

O que mudou, eu era uma pessoa muito ativa sexual, mas fazer o que, é outra coisa. (Participante J)

Os temores mais frequentes em pacientes com o diagnóstico de câncer de próstata são em relação à disseminaçáo da doença e à mudança da sensibilidade sexual ${ }^{18}$. Além disso, alguns homens ainda têm dificuldade e sentem-se constrangidos ao falar com os profissionais de saúde sobre os impactos acometidos pelo tratamento.

\section{Área temática 3 - Mudanças no estilo de vida: um longo caminho}

A temática "estilo de vida", referente às condições de vida, representa um desafio para muitas pessoas. Contempla a saúde física, mental e espiritual, educação, questóes financeiras, além do equilíbrio entre o lado pessoal e profissional. A concretização desses aspectos pressupóe algumas medidas, entre as quais adotar hábitos saudáveis, reservar tempo para cultura e lazer, para o trabalho e cultivar relaçóes sociais e familiares positivas e consistentes.

Para $\operatorname{Prado}^{19}$, o câncer é uma doença silenciosa que afeta as pessoas do "mundo industrializado". O autor ressalta que há alguns fatores predisponentes, tais como: substâncias químicas presentes no fumo, conservantes de carnes e embutidos, a luz ultravioleta do sol, além das bebidas alcoólicas. São também agentes cancerígenos vários tipos de substâncias químicas, dentre as quais herbicidas, pesticidas e fungicidas que, utilizadas de forma indiscriminada pelos agricultores no cultivo de verduras, hortaliças e demais produtos destinados ao consumo humano, podem gerar tumores malignos. $\mathrm{O}$ pesquisador ainda aponta que: "O único tumor que apresenta relaçáo positiva e direta com a ingestáo de gordura é o câncer de próstata" ${ }^{19}$. Uma alimentação adequada, variada e equilibrada contribui na manutenção da qualidade de vida, diminuindo a possibilidade da incidência do câncer de próstata.

No que se refere ao estilo de vida saudável ou não, os participantes relatam:

Eu só bebo em festas. (Participante A)

Fumo só três cigarros por dia. (Participante B)

Já bebi muito. Hoje, pouco, socialmente, quatro ou cinco vezes no mês. Bebo todos os dias uma pinga de butiá. (Participante C)

Fumei, mais ou menos, a sete anos atrás. (Participante D)

Bebo com moderação, sábado e domingo. (Participante E)

Fumo 10 cigarros, diminui, mas não consigo parar de fumar. (Participante F)

Há 24 anos não bebo, $e$ há 10 anos não fumo. (Participante G)

Antigamente fumava 10 cigarros por dia, naquela época, há mais de 25 anos, agora não fumo. (Participante $\mathrm{H}$ )

Antes do AVC, bebia três cervejas por dia, todo dia. Até 50 anos, fumava uma carteira de cigarros por dia, antes do $A V C$. (Participante I)

Fumei 45 anos, um maço, uma carteira de cigarros. (Participante J)

Para Prado ${ }^{19}$, quando o assunto é risco de câncer, náo existe "cigarro light" ou "cigarro menos nocivo", porque todos provocam a neoplasia. A exposição à fumaça do cigarro, prolongada ou náo, de forma ativa ou passiva, pode causar câncer. $\mathrm{O}$ autor ressalta que um dos fatores de risco, também relacionados ao desenvolvimento de câncer, é o consumo de álcool, excessivo ou moderado. O álcool pode agir na evolução da doença de diversas maneiras, tais como: alterar o DNA e originar células defeituosas, causando danos e lesôes no fígado, que, ao serem reparadas pelo organismo, geram células cancerígenas; e dissolver substâncias que fazem mal ao organismo, fazendo que estas se espalhem mais facilmente.

No que se refere à atividade física, $50 \%$ dos participantes relataram a prática de caminhada, alongamento, 
esteira, jogar bocha e andar de bicicleta. No entanto, os outros $50 \%$ afirmam não realizar nenhum tipo de atividade física.

Para Prado $^{19}$, a falta de atividade física é responsável pela manifestaçáo de alguns tipos de câncer, mesmo em pessoas com peso adequado. $\mathrm{O}$ exercício físico regular está associado à diminuição do risco de câncer, tendo efeitos positivos em sua prevenção, além de contribuir para a manutençáo da saúde, combatendo o sedentarismo e possibilitando o bem-estar físico.

\section{Área temática 4 - Família: o câncer em nossas vidas}

No diagnóstico de câncer de próstata, o apoio da família é essencial para o enfrentamento da doença. Como as mulheres, por questão de gênero, cuidam mais da saúde do que os homens, esse apoio é fundamental para encorajá-los no tratamento. $\mathrm{O}$ acometimento pelo câncer pode contribuir significativamente para a desestruturação da base familiar em decorrência do sofrimento de todos os envolvidos.

Para Mathias, Beuter e Girardon-Perlini ${ }^{20}$, "o carinho, o amor, a proteção, a união, a fé, o estar junto, descrevem o cuidar e se constituem uma prática de cuidado essencial para a pessoa com câncer”. Ressaltam também que as mudanças no cotidiano familiar possibilitam o enfrentamento e o sentimento de pertencimento do companheiro/pai no núcleo da família.

Neste estudo, os homens relataram que receberam apoio familiar desde o início do diagnóstico, o que possibilitou a melhor adesão ao tratamento, conforme evidenciado nestas falas:

Tenho apoio da esposa e do filho. (Participante A)

Meu apoio vem da esposa, dos filhos, das noras, de todos. (Participante C)

Tenho, da minha esposa e filhos, sou otimista, não fico botando coisa na cabeça. (Participante F)

Sim, tenho apoio do meu irmão, através dos filhos, da minha ex-mulher e da ex-namorada, na época. (Participante J)

A principal fonte de apoio para o homem diagnosticado com câncer de próstata é a família, que, ao mesmo tempo, torna-se facilitador e fortalecedor da relação do binômio paciente-cuidador, considerado uma unidade de atenção, por ser um sistema de cuidado invisível da saúde, em que o câncer deve ser tratado como problema e questão familiar. $\mathrm{O}$ cuidador pode ser o cônjuge, outros membros familiares e amigos próximos que, participando ativamente, dão forma à experiência com a doença ${ }^{17}$.

Em outros estudos, a família é apontada como elo fundamental no contexto das influências das pessoas que vivenciam os efeitos da doença, que cruzam o caminho de quem luta contra o câncer; podendo conceder esperança ao paciente por estar presente no acompanhamento do tratamento ${ }^{21}$.

\section{Área temática 5 - O câncer de próstata e as redes de apoio}

As redes sociais de apoio são importantes instrumentos para o enfrentamento das mudanças psicossociais vivenciadas pelos homens com câncer de próstata.

A família e a rede de apoio social, atuando desde o início da constatação da doença, são destacadas como as principais fontes de amparo. Assim, auxiliam a pessoa a adaptar-se aos rigores do tratamento, diminuindo o estresse e favorecendo uma melhor qualidade de vida. A religião também pode ser uma rede de apoio ${ }^{22}$.

Em relação ao apoio religioso, três dos participantes relataram buscar forças através da fé como forma de enfrentamento após o diagnóstico da doença, tornando melhor a adesão ao tratamento. A manutenção da crença e as práticas espirituais de uma religião de oraçóes, meditaçôes e participação em rituais e outras atividades fortalece a conexão com o sagrado, a reflexão crítica orientada e a aceitação da situação de forma mais flexível. A religiosidade pode servir de apoio social, porque provê acesso às redes sociais e estabelece formas de assistência, como cuidado espiritual nas fases de angústia aguda ${ }^{17}$.

Segundo Moscheta e Santos ${ }^{22}$, as redes de apoio podem ser constituídas nos contextos de saúde, como hospitais e unidades básicas de saúde, ou no âmbito da comunidade, em associaçóes de bairros ou grupos sociais organizados. Normalmente os homens buscam informaçôes, orientaçóes, opiniōes, encorajamento, compartilhamento de experiências e apoio psicológico nessas redes. As redes de apoio mencionadas pelos participantes da pesquisa foram: ambulatório do Hospital Municipal São José, serviços de saúde públicos e privados, equipes de saúde e Rede Feminina de Combate ao Câncer de Sáo Francisco do Sul. Vale destacar que os participantes $\mathrm{A}$ e $\mathrm{D}$ não responderam.

Para Thalenberg ${ }^{23}$ é inegável que uma doença dessa natureza seja um atravessamento nas vidas das pessoas. Sendo assim, é preciso considerar que esse sofrimento também se estende a outras pessoas, como companheiros, familiares e amigos. E é justamente nesse ponto que a noção de rede toma sentido. Sua construção tem dupla 
finalidade: deve tanto servir de suporte para o paciente como também para sua autossustentaçáo. Outra rede de apoio que já mencionamos pode ser a religiosidade.

\section{Área temática 6 - Percepções e sentimentos dos homens diagnosticados com câncer de próstata}

Durante a realização deste estudo, os participantes foram revelando os sentimentos vivenciados com o diagnóstico e o tratamento. Porém, dois deles declaram que não houve mudança no seu cotidiano. Os temores mais frequentes em pacientes diagnosticados com câncer de próstata estão relacionados à disseminaçáo da doença e à mudança da sensibilidade sexual ${ }^{18}$.

A partir dos relatos dos participantes, nota-se que eles vivenciam momentos difíceis com a descoberta da doença. Os principais sentimentos referidos pelos homens foram: negação, medo da morte, receio/dúvida, ansiedade, falta de esclarecimento, preconceito, tristeza, perda da sexualidade e fé. Ou seja, o sofrimento do homem portador de câncer de próstata afeta seu bem-estar físico e emocional.

$O$ viver religioso faz com que a gente não se preocupa. Quando novo, fui para o seminário, a vida religiosa ajuda muito as pessoas. (Participante A)

Tive ansiedade e falta de esclarecimento. (Participante C)

Não mudou nada, tô perfeito, tô saudável, acreditei em Deus. (Participante E)

Tive receio, desconhecimento, dúvida, um pouco. (Participante F)

Tive preconceito e fiquei triste, doença relativa, todos os homens têm. (Participante G)

Tenho medo de morrer e deixar os netos, deixar eles. (Participante I)

Penso diferente, nada se perde, tudo se transforma, eu acredito em Deus, entendeu? (Participante J)

Para Tofani e Vaz ${ }^{18}$, o tratamento do câncer de próstata afeta a masculinidade, visto que muitos ficam com impotência sexual. Além disso, alguns homens percebem a relação sexual como uma obrigação, e focam o prazer apenas na rigidez do pênis e na intensidade do orgasmo. Essa preocupação aumenta o nível de ansiedade, com a possibilidade de bloquear a resposta sexual.
Ao conhecer o diagnóstico de câncer de próstata, o primeiro mecanismo de defesa do homem é a negação, que funciona como uma proteçáo. Porém, se esse mecanismo persistir, pode enfraquecer os relacionamentos interpessoais e impedir que o paciente assuma uma atitude mais responsável sobre a sua saúde ${ }^{18}$. Com o diagnóstico, é comum que o paciente sinta-se estigmatizado, uma vez que, culturalmente, a doença está associada à morte ${ }^{22}$.

A prevenção e o tratamento do câncer de próstata devem dar atenção aos aspectos emocionais envolvidos, visto que muitos homens adiam ou mesmo recusam a participar de programas preventivos. Embora haja muita falta de informação, são as fantasias de conflitos associados aos exames clínicos e à próstata que sustentam a resistência ao tratamento médico ${ }^{4}$. As implicações e incertezas que perpassam o diagnóstico de câncer e intensificam as reaçôes emocionais com o choque ou descrença ante a descoberta do tumor estáo associadas a sintomas de ansiedade, tristeza e irritabilidade ${ }^{18}$.

Os homens ainda sabem pouco sobre o câncer de próstata e seus fatores de risco; existem muitos mitos tabus e preconceitos em torno da doença. Muitos sentimentos afetam os homens diagnosticados com câncer e suas famílias, tais como a depressáo e o sentimento de impotência. Assim, a escuta sensível e o diálogo sobre a doença são fundamentais para uma assistência mais humanizada e integral ${ }^{4}$.

As dificuldades encontradas na adesão à prevenção e no acesso às unidades de saúde levam a população masculina ao descuido com a saúde, e envolvem fatores como crenças, cultura e os tabus relacionados aos exames para diagnóstico do câncer de próstata ${ }^{24}$.

Dois participantes mencionaram necessidade de se afastar de suas atividades profissionais, mas outros dois não encontraram dificuldades nesse sentido, referindo que nada mudou com o diagnóstico e tratamento da doença.

O homem com câncer tem direitos sociais garantidos, entre os quais o auxílio-doença, benefício mensal oferecido a quem fica temporariamente incapaz para o trabalho em decorrência da doença por mais de 15 dias consecutivos. Sendo assim, terá direito ao benefício, independentemente do pagamento de 12 contribuiçóes, desde que esteja na qualidade de segurado. A incapacidade para o trabalho deve ser comprovada por meio de exame realizado pela perícia médica do INSS ${ }^{25}$.

O câncer, como doença crônico-degenerativa, pode impor aos pacientes e familiares um enorme desafio de enfrentamento. A enfermagem precisa ouvir os pacientes e seus familiares, identificar as redes problemáticas e auxiliá-los nas orientaçóes sobre a doença, mobilizando redes de apoio para que enfrentem da melhor maneira a convivência com esse agravo ${ }^{26}$. 


\section{Conclusões}

Neste estudo procuramos compreender as formas de enfrentamentos, adaptaçóes e mudanças decorrentes do câncer de próstata por meio de relatos de dez homens que se dispuseram a participar da pesquisa.

Segundo as características dos participantes, identificamos que três deles tinham idade entre 60 e 65 anos, o que corrobora outros estudos de autores que referem esse tipo de câncer como predominante da terceira idade.

Observou-se que os homens não buscam serviços de atenção primária com frequência, apesar da vulnerabilidade e das altas taxas de morbimortalidade, o que pode acarretar o agravo da doença pela demora na atençáo e, consequentemente, maior custo para o sistema de saúde.

Foi constatado que os participantes vivenciam sentimentos de negação, medo da morte, receio, dúvida, ansiedade, falta de esclarecimento, preconceito, tristeza, perda da sexualidade e fé - o que evidencia o sofrimento no enfrentamento da doença.

Considerando as áreas temáticas apresentadas neste trabalho, tornou-se evidente que o maior impacto relatado pelos participantes está relacionado à sexualidade (disfunção erétil).

Os homens entrevistados referiram também que o apoio familiar favorece a luta contra a doença. E ressaltaram que, em Joinville, não existe uma rede de apoio específico para tratar o acompanhamento psicológico. Ademais, apontam suas crenças religiosas como rede de apoio no enfrentamento da neoplasia.

O estudo evidencia a importância da assistência individualizada e humanizada prestada pelo profissional de saúde à pessoa com câncer, bem como a relevância da escuta sensibilizada. É necessário compreender os sentimentos dessas pessoas e as situaçóes vivenciadas por elas, apoiando-as para que possam planejar cuidados compartilhados, a fim de favorecer a adesão ao tratamento e enfrentamento da doença.

\section{Referências}

1. Instituto Nacional de Câncer [homepage na Internet]. O que é o câncer? [citado em 2015 set 25]. Disponível em: https://goo.gl/UbNZ15

2. Pinto BK, Muniz RM, Schwartz E, Budó MLD, Heck RM, Lange C. Identidade do homem resiliente no contexto de adoecer por câncer de próstata: uma perspectiva cultural. Rev Bras Enferm. [Internet]. 2014 Nov-Dez [citado em 2015 set 11]; 67(6):942-8. Disponível em: https://goo.gl/Lp7HvN

3. Instituto Nacional de Câncer [homepage na Internet]. Próstata. [citado em 2015 set 25]. Disponível em: https:// goo.gl/NjXcyT
4. Vieira CG, Araújo WS, Vargas DRM. O homem e o câncer de próstata: prováveis reaçóes diante de um possível diagnóstico. Rev Cient Itpac. [Internet]. 2012 Jan [citado em 2016 out 27];5(1):1-9. Disponível em: https://goo.gl/ HjspMn

5. Gianini MMS. Câncer e gênero: enfrentamento da doença [dissertação]. São Paulo: Pontifícia Universidade Católica de São Paulo; 2007. [citado em 2016 fev 11]. Disponível em: https://goo.gl/yf4XYZ

6. Minayo MCS. O desafio do conhecimento: pesquisa qualitativa em saúde. $8^{a}$ ed. São Paulo: Hucitec; 2004.

7. Gonçalves IR, Padovani C, Popim RC. Caracterização epidemiológica e demográfica de homens com câncer de próstata. Ciênc Saúde Coletiva. 2008 Jul-Ago [citado em 2016 out 7];13(4):1337-42. Disponível em: https://goo.gl/ DLDJi1

8. Fornazari SA, Ferreira RER. Religiosidade/espiritualidade em pacientes oncológicos: qualidade de vida e saúde. Psicol Teor Pesqui. 2010 Jun [citado em 2016 out 7];26(2):26572. Disponível em: https://goo.gl/L2pzIl

9. A.C. Camargo Câncer Center [homepage da Internet]. Impactos do diagnóstico e do tratamento do câncer de próstata na masculinidade. [citado em 2016 nov 25]. Disponível em: https://goo.gl/W5tJxI

10. Damião R, Figueiredo RT, Dornas MC, Lima DS, Korschorke MAB. Câncer de próstata. Med HUPE-UERJ [Internet]. 2015 ago 31 [citado em 2016 nov 25];14(1):806. Disponível em: https://goo.gl/TReowU

11. Bastian Júnior AJ. Novembro azul polêmico: desserviço da desinformação. AMB [Internet]. 2015 Nov 25 [citado em 2016 out 30]. Disponível em: https://goo.gl/AnWUJL

12. Brasil. Ministério da Saúde. Secretaria de Assistência à Saúde. Instituto Nacional do Câncer. Programa Nacional de Controle do Câncer da Próstata: documento de consenso. Rio de Janeiro: Inca; 2002.

13. Brasil. Ministério da Saúde. Instituto Nacional do Câncer. Açóes de enfermagem para o controle do câncer: uma proposta de integração ensino-serviço. $3^{\mathrm{a}} \mathrm{ed}$. Rio de Janeiro: CEDC; 2008. [citado em 2016 set 14]. Disponível em: https://goo.gl/bveDNn

14. Santos DRF, Silva FBL, Saldanha EA, Lira ALBC, Vitor AF. Cuidados de enfermagem ao paciente em pós-operatório de prostatectomia: revisão integrativa. Rev Eletrônica Enferm. [Internet]. 2012 Jul-Set [citado em 2016 set 12];14(3):690701. Disponível em: https://goo.gl/akMl28

15. Batista DRR, Mattos M, Silva SF. Convivendo com o câncer: do diagnóstico ao tratamento. Rev Enferm UFSM. 2015 Out [citado em 2016 set 12];5(3):499-510. Disponível em: https://goo.gl/XVXDV9

16. Franco RC, Souhami L. Radioterapia e hormonioterapia no câncer de próstata de risco intermediário: uma revisão crítica. Rev Bras Cancerol. 2015 Jun [citado em 2016 out 10];2(61):155-63. Disponível em: https://goo.gl/M03xA5 
17. Sanchez KOL, Ferreira NMLA, Dupas G, Costa DB. Apoio social à família do paciente com câncer: identificando caminhos e direçóes. Rev Bras Enferm. 2010 Mar [citado em 2016 out 24];2(63):290-9. Disponível em: https://goo.gl/ UaWGKr

18. Tofani ACA, Vaz CE. Câncer de próstata, sentimento de impotência e fracassos ante os cartóes IV e VI do Rorschach. Interam J Psychol. 2007 Ago [citado em 2016 out 25];41(2):197-204. Disponível em: https://goo.gl/ pXCVdn

19. Prado BBF. Influência dos hábitos de vida no desenvolvimento do câncer. Ciênc Cult. 2014 [citado em 2016 out 26];66(1):21-4. Disponível em: https://goo.gl/dTTw5b

20. Mathias CV, Beuter M, Girardon-Perlini NMO. Experiência da família rural ao ter o pai/esposo com câncer de próstata. Rev Rene. 2015 Set 30 [citado em 2016 out 29];16(4):48695. Disponível em: https://goo.gl/BqOAPd

21. Sales CA, Cassarotti MS, Piolli KC, Matsuda LM, Wakiuchi J. O sentimento de esperança em pacientes com câncer: uma análise existencial. Rev Rene. 2014 Out 13 [citado em 2016 out 29];15(4):659-67. Disponível em: https://goo.gl/ VVL94G
22. Moscheta MS, Santos MA. Grupos de apoio para homens com câncer de próstata: revisão integrativa da literatura. Ciên Saúde Coletiva. 2012 Maio [citado em 2016 out 27];17(5):1225-33. Disponível em: https://goo.gl/WcBrgO

23. Thalenberg LGK. A rede de apoio no tratamento oncológico. Interface Comun Saúde Educ. 2010 Set [citado em 2016 out 28];14(34):713-15. Disponível em: https://goo. $\mathrm{gl} / \mathrm{ZIztL} 2$

24. Theobaldo FM, Girotti PA, Morbio AP. Atuação da enfermagem na prevenção do câncer de próstata. Rev Cient Elet Ciênc Aplic Fait. 2014 Abr [citado em 2016 out 28];51(16):1-10. Disponível em: https://goo.gl/GMtd5Y

25. Brasil. Ministério da Saúde. Secretaria de Assistência à Saúde. Instituto Nacional de Câncer José Alencar Gomes da Silva. Direitos sociais da pessoa com câncer: orientaçôes aos pacientes. $4^{a}$ ed. Rio de Janeiro: Inca, 2014 [citado em 2016 set 20]. Disponível em: https://goo.gl/ymhZKZ

26. Costa P, Leite RCBO. Estratégias de enfrentamento utilizadas pelos pacientes oncológicos submetidos a cirurgias mutiladoras. Rev Bras Cancerol. 2009 Ago 27 [citado em 2016 nov 25];55(4):355-64. Disponível em: https://goo.gl/ CUybEr

\section{Como citar este artigo:}

Serafim DP, Cardozo LMW, Schumacher B. Homens com diagnóstico de câncer de próstata: enfrentamentos e adaptações. Rev. Aten. Saúde. 2017;15(52):29-37. 